\title{
The Paris Agreement: A New Beginning?
}

\author{
Annalisa Savaresi
}

This is an Accepted Manuscript of an article published by Taylor \& Francis Group in Journal of Energy \& Natural Resources Law on 29/01/2015, available online: http://www.tandfonline.com/doi/full/10.1080/02646811.2016.1133983 


\begin{abstract}
The Paris Climate Change Conference was tasked to set the world on a path to address the greatest challenge to ever face humankind, by adopting a new climate agreement. The outlook for the conference was rather bleak. The laborious and increasingly frequent meetings of the body entrusted to draft the text of the Paris Agreement, the Ad Hoc Working Group on the Durban Platform for Enhanced Action (ADP), had made limited progress. These negotiations had eloquently demonstrated the futility of technical negotiations, without political consensus on the core elements and features of the new agreement. Yet, to the surprise of many, the Paris Conference concluded on 12 December 2015, with the adoption of a new climate treaty. This article reflects on the Paris Conference and on its outcome. First, it collocates the conference in the history of the climate regime. Then, it explains what Parties were expected to deliver. Finally, it assesses the outcome of the conference against these expectations. The article concludes with a reflection on where the climate regime is likely to head next, and where the Paris Agreement leaves Parties in their efforts to tackle climate change.
\end{abstract}

\title{
Keywords
}

Climate change, Paris Agreement, Paris Conference 


\title{
The Paris Agreement: A New Beginning?
}

\author{
Annalisa Savaresi ${ }^{1}$
}

\section{From Kyoto to Paris, via Copenhagen}

Ever since 1992, Parties to the United Nations Framework Convention on Climate Change $(\mathrm{UNFCCC})^{2}$ have attempted to agree on measures to stabilize greenhouse gas concentrations in the atmosphere at a level that would prevent 'dangerous anthropogenic interference with the climate system. ${ }^{3}$ The international scientific body entrusted to assess climate change, the Intergovernmental Panel on Climate Change (IPCC), has indicated that such a level requires keeping the increase in global annual average temperature below $2^{\circ} \mathrm{C}$ as compared with preindustrial times. ${ }^{4}$ However, the UNFCCC has struggled to keep the world within the limits indicated by the IPCC.

The reason international climate governance has proven to be such an intractable affair relates both to the enormity of the challenge at hand, as well as to the gaping disparity in states' capacity to tackle climate change. There is an inherent disproportion both in the projected impacts of climate change across countries and in the means to cope with such impacts and to contribute to climate change mitigation. The main instrument adopted to stabilize greenhouse gas concentrations in the atmosphere under the UNFCCC, the 1997 Kyoto Protocol, ${ }^{5}$ fundamentally acknowledged this gap. Building upon a static differentiation between 'developed' and 'developing' countries embedded in the Convention, ${ }^{6}$ the Protocol imposed binding emission reduction targets only on the first. With ever growing emissions in emerging economies, like China and India, however, scientists have repeatedly flagged that reducing emissions in developed countries only would not be enough.

To make matters worse, over the years political will behind the Kyoto Protocol has significantly faltered. After the elapse of the first commitment period in 2012, it has proven impossible to negotiate new targets for some important players, such as Japan, New Zealand and the Russian Federation, whereas others, namely Canada and the US, are not even Parties to the Protocol. This situation has left the European Union and a few other developed countries, like Australia, Norway and Switzerland, in the uncomfortable position of being the sole Parties to the Protocol with emission reduction targets under the Kyoto Protocol. ${ }^{7}$

In the hope of inducing more states to reduce their emissions, in 2007 UNFCCC Parties embarked upon the difficult process of negotiating measures to achieve the objective

\footnotetext{
1 Annalisa Savaresi, PhD, Research and Teaching Fellow, University of Edinburgh Law School.

${ }^{2}$ UN Framework Convention on Climate Change (Rio de Janeiro, 9 May 1992, in force 21 March 1994) 1771 UNTS 107.

${ }^{3}$ UNFCCC, Article 2.

${ }^{4}$ Martin L. Parry et al., 'Contribution of Working Group II to the Fourth Assessment Report of the Intergovernmental Panel on Climate Change' (Cambridge University Press, 2007), at 19.4.2.2.

${ }^{5}$ Kyoto Protocol (Kyoto, 11 December 1997, in force 16 February 2005) 2303 UNTS 262.

${ }^{6}$ UNFCCC, Annexes I and II.

${ }^{7}$ Doha Amendment to the Kyoto Protocol, (Doha, 2012), not yet into force
} 
of the Convention. ${ }^{8}$ These negotiations suffered numerous setbacks and almost collapsed in 2009 in Copenhagen. Subsequent negotiations opened the way to a new geometry of commitments, based on a new approach to differentiation between Parties. ${ }^{9}$ The adoption of a treaty including emission reduction commitments for all Parties, however, was but one of the possible outcomes opened up by the new negotiation scenario.

The Paris Climate Change Conference was expected to bring to a conclusion this cycle of negotiations, by adopting 'a protocol, another legal instrument or a legal outcome' applicable to 'all Parties,' to be implemented from 2020. ${ }^{10}$ The ADP, the body tasked with the development of the text for the agreement, met 15 times to try and complete this endeavour. In February 2015 the ADP adopted a negotiating text for the Paris Agreement ${ }^{11}$ an indispensible formality, should Parties decide to adopt the agreement as a protocol to the UNFCCC.

This sizeable 90 page negotiating text was hastily compiled on the basis of UNFCCC Parties' submissions. Subsequent ADP sessions were dedicated to trying to turn this chaotic text into that of a legal instrument to be adopted in December 2015. Finding a mode of work suited to negotiate a text based on the mechanical compilation of Parties' submissions, with hardly any common ground on fundamental choices regarding the nature and the content of Parties' obligations, was a veritable conundrum. A variety of approaches to streamline, cluster and reduce the size of the negotiating text were experimented with, but only delivered limited results.

The last ADP session before Paris delivered a draft text for a 'package' including a draft UNFCCC Conference of the Parties (COP) decision adopting the agreement and a cluttered 31 page draft treaty text, featuring little consensus on any of the core elements of the Paris Agreement, and no overall sense of direction. ${ }^{12}$

\section{Laying the ghosts of the past to rest}

Ahead of the Paris Climate Change Conference, many evoked memories of the difficult negotiations that preceded the Copenhagen Climate Change Conference in 2009. There were, however, fundamental differences between the negotiation process that preceded the Copenhagen conference and that preceding Paris.

Ahead of Copenhagen, it had been impossible to formally adopt a negotiating text. As a result, delegates had to work with a voluminous text of over 200 pages, based on an unofficial compilation of Parties' submissions. As no progress on text negotiations could be made, the Copenhagen Conference was haunted with rumours about a possible 'Danish text' that the presidency might table at the eleventh hour. The ensuing break-down in trust and diplomatic mismanagement of the process led the conference to conclude with a non-

\footnotetext{
${ }^{8}$ Decision 1/CP.13, Bali Action Plan, FCCC/CP/2007/6/Add.1.

${ }^{9}$ Decision 1.CP/17, Establishment of an Ad Hoc Working Group on the Durban Platform for Enhanced Action, $\mathrm{FCCC} / \mathrm{CP} / 2011 / 9 /$ Add. 1

${ }^{10}$ Ibid., at 2 and 4.

${ }^{11}$ Negotiating Text, FCCC/ADP/2015/1, 25 February 2015.

12 Draft agreement and draft decision on workstreams 1 and 2 of the Ad Hoc Working Group on the Durban Platform for Enhanced Action Work of the ADP contact group, available at: $<$ http://unfccc.int/resource/docs/2015/adp2/eng/11infnot.pdf $>$
} 
inclusive, untransparent, last-minute political agreement, known as the Copenhagen Accord, which marked the low-point in the history of the climate regime. ${ }^{13}$

Contrariwise, ahead of Paris, a negotiating text had been formally adopted. The negotiating text produced by the ADP seemingly suggested that the outlook for Paris was more favourable than that for Copenhagen. Still, while formally UNFCCC Parties were in a much better position than they were ahead of Copenhagen, politically their situation seemed just as hopeless. The work of the ADP had shown that consensus on how to collectively tackle climate change remained distant, as Parties' views on fundamental substantive issues significantly diverged.

The veritable bone of contention undoubtedly was the question of differentiation. States' views still greatly differed on how to distribute the burden to mitigate climate change, as well as to provide capacity building, finance and technology to those in need. On the one end of the spectrum, numerous developed and developing countries converged on the need to move beyond a 'bifurcated approach' to differentiation, even though not on how this ought to be done. On the other end of the spectrum, some developing countries vehemently opposed considering moving beyond existing differentiation parameters.

Even more critically, Parties struggled to find consensus on an overarching architecture to capture their 'nationally determined contributions' (NDCs). ${ }^{14}$ NDCs are meant to provide information on what each Party to the Paris Agreement intends to do to tackle climate change. At the aggregate level, however, submissions made ahead of the Paris Conference remained far from a level of ambition consistent with the $2^{\circ} \mathrm{C}$ goal. ${ }^{15}$ Still, ADP negotiations could not agree on a process to review and adjust States' contributions to enable the achievement of the goal.

Finally, ahead of Paris, negotiators could not come to a common understanding on whether the Paris Agreement ought to be a protocol to the UNFCCC or not. With no common vision on all of these issues, the ADP process had eloquently demonstrated the futility of technical negotiations, without prior political consensus on the core elements and features of the Paris Agreement. Delegates in Paris were therefore left with the task of laying the ghosts of the past to rest, and adopting an agreement that resolved or set aside all contentious issues. On the eve of the conference, few would have expected them to succeed in this task. Yet, to the surprise of many, they did. The following sections provide a short analysis of the process that led to the adoption of the agreement, as well as of its core elements.

\section{The making of the Paris Agreement}

When the ADP formally closed at the end the first week of the Paris Conference, it produced a negotiating text of 48 pages, with more than 900 square brackets. ${ }^{16}$ Given these

\footnotetext{
${ }^{13}$ Lavanya Rajamani, 'The Making and Unmaking of the Copenhagen Accord' (2010) 59 International and Comparative Law Quarterly 824.

${ }^{14}$ Parties' submissions may be accessed here: $<$ http://unfecc.int/focus/indc_portal/items/8766.php $>$ accessed 15 December 2015.

${ }^{15}$ Synthesis Report on the Aggregate Effect of the Intended Nationally Determined Contributions, $\mathrm{FCCC} / \mathrm{CP} / 2015 / 7$.

${ }^{16}$ The negotiating text delivered by the ADP may be accessed at: http://unfccc.int/resource/docs/2015/adp2/eng/106r01.pdf
} 
disheartening premises, it seemed unlikely that the conference would conclude with the adoption of a treaty.

However, by the end of the second week, the UNFCCC COP formally adopted the Paris Agreement as a treaty. This remarkable outcome was the result of a herculean diplomatic effort by the numerous ministers representing the 196 Parties to the UNFCCC and gathered in Paris for a whole week. With technical negotiations virtually stalled, the presence of ministers was indispensible to reach political compromise and bridge differences between parties' entrenched positions, and, ultimately, to deliver the political compromise the ADP had been unable to facilitate. In this regard, the strategy to hold the high level segment with 150 heads of state and government in the beginning, rather than in the end of the conference, turned out to be a success. Admittedly, however, the consensus building process did not start in Paris and was facilitated by a plethora of diplomatic multilateral and bilateral gatherings over the last couple of years. Nonetheless, the pace of progress in the last week of negotiations in Paris was truly remarkable, and many rightfully praised the French Presidency for its skilful management of the diplomatic process at such a critical junction. The outcome was also undoubtedly aided by the unprecedented political will underpinning the process, which saw 100 between developed and developing countries rolling up their sleeves to reach compromise, by working in an unprecedented coalition, which included the US, as well as small developing island states and the EU. ${ }^{17}$

\section{Paris Agreement: core elements}

The Paris Agreement is a lean 11 page treaty, consisting of 29 articles and 16 preambular paragraphs. The treaty text is annexed to a 20 page COP decision that formally adopts the agreement and addresses a number of technical and substantive matters to give effect to it. The operative provisions of the Paris Agreement cover the substantive issues of mitigation, adaptation and means of implementation (capacity building, finance, and technology transfer). The remainder of the agreement includes a host of procedural and institutional arrangements. The following sections provide an early and non-exhaustive review of the main provisions in the Paris Agreement, starting with an assessment of its legal form.

\section{Legal form}

In spite of much speculation to the contrary, ${ }^{18}$ as a treaty ${ }^{19}$ the Paris Agreement will be formally binding upon its Parties, even though the scope of states' obligations will clearly

\footnotetext{
${ }^{17}$ Karl Mathiesen and Fiona Harvey, 'Climate Coalition Breaks Cover in Paris to Push for Binding and Ambitious Deal' The Guardian (8 December 2015)

$<$ http://www.theguardian.com/environment/2015/dec/08/coalition-paris-push-for-binding-ambitious-climatechange-deal $>$ accessed 15 December 2015.

${ }^{18}$ As reported in Joust Pauwelyn and Lilliana Andonova, 'A 'Legally Binding Treaty' or Not? The Wrong Question for Paris Climate Summit' <http:/www.ejiltalk.org/a-legally-binding-treaty-or-not-the-wrongquestion-for-paris-climate-summit/> accessed 14 December 2015.

${ }^{19}$ Vienna Convention on the Law of Treaties (Vienna, 23 May 1969, in force 27 January 1980) 115 UNTS 331, Article 2.1.a.
} 
depend on the interpretation of the language in each provision. ${ }^{20}$ While in fact some provisions unequivocally assert obligations - for example, the obligation of means to pursue domestic mitigation action ${ }^{21}$ - others are expressed in less categorical terms - for example, those concerning developed countries' leadership in undertaking mitigation action, or developing countries move towards emission reduction targets. ${ }^{22}$ Others again have a clearly enabling character, and are merely meant to facilitate internationally coordinated action, rather than prescribing it - such as, for example, cooperation in the implementation of NDCs. ${ }^{23}$

More generally, the Paris Agreement leaves ample leeway to Parties on how to undertake action to tackle climate change. Still for the first time it enshrines in treaty text a global commitment 'to reach global peaking of greenhouse gas emissions as soon as possible, ${ }^{24}$ making specific reference to the $2{ }^{\circ} \mathrm{C}$ goal, and even an aspirational reference to the $1,5^{\circ} \mathrm{C}$ goal. ${ }^{25}$

So is the Paris Agreement a protocol to the UNFCCC? This issue is not explicitly addressed in the agreement. Yet, some of its provisions seem to suggest that it is a protocol in everything but name. This conclusion is suggested by cross references to the UNFCCC, ${ }^{26}$ whose objective and enhanced implementation the Paris Agreement explicitly sets out to achieve. ${ }^{27}$ Even more evidence in this connection comes from the institutional arrangements in the Paris Agreement, ${ }^{28}$ which largely build upon those made under the UNFCCC. Finally, the entry into force of the Paris Agreement is subjected to ratification by at least 55 Parties to the UNFCCC, accounting at least for 55 per cent of total greenhouse gas emissions. ${ }^{29}$ Others in Paris suggested that the agreement be regarded as an implementing agreement to the UNFCCC. Eventually, delegates opted for avoiding diatribes on legal form and for referring to the new treaty simply with the term 'agreement'.

\section{Overarching architecture}

The Paris Agreement has set the bases for a new 'hybrid' architecture ${ }^{30}$ bringing together all Parties' contributions under a unitary framework enabling the periodical review of action and the ratcheting up of ambition. This new architecture largely builds on and consolidates developments occurred in recent years. Ever since the ill-fated Copenhagen Climate Change Conference in 2009 , in fact, the climate regime has progressively moved away from the "top-

\footnotetext{
${ }^{20}$ Daniel Bodansky, 'The Legal Character of the Paris Agreement: A Primer'

$<$ http://opiniojuris.org/2015/12/02/the-legal-character-of-the-paris-agreement-a-primer/> accessed 14 December 2015.

${ }^{21}$ Paris Agreement, Article 4.2.

${ }^{22}$ Paris Agreement, Article 4.4.

${ }^{23}$ Paris Agreement, Article 6.

${ }^{24}$ Paris Agreement, Article 4.1.

${ }^{25}$ Paris Agreement, Article 2.1(a).

${ }^{26}$ See, for example, Paris Agreement, Articles 1 and 2.

${ }^{27}$ Paris Agreement, Article 2.

${ }^{28}$ Paris Agreement, Article 16-18.

${ }^{29}$ Paris Agreement, Article 21.1.

${ }^{30}$ This terminology is used in Daniel Bodansky, 'The Durban Platform: Issues and Options for a 2015 Agreement' (Social Science Research Network 2012) SSRN Scholarly Paper ID 2270336 $<$ http://papers.ssrn.com/abstract=2270336> accessed 24 September 2015.
} 
down' governance model embedded in the Kyoto Protocol. ${ }^{31}$ The Protocol relied on a 'targets and timetables' approach, imposing reduction commitments only on some developed country Parties. ${ }^{32}$ The political will to support the furtherance of this approach, however, has over the years significantly faltered.

With the slow but inexorable phasing-out of the targets and timetables approach embedded in the Kyoto Protocol, ${ }^{33}$ Parties to the climate regime have increasingly moved towards a 'pledge and review' approach to climate governance. This new approach entails that UNFCCC Parties unilaterally declare the action they are willing to undertake, turning on its head the top-down approach embedded in the Kyoto Protocol. ${ }^{34}$ In this process, the UNFCCC machinery works as a 'notary' collecting, and eventually enabling the peer review of the implementation of Parties' pledged action. This 'bottom up' approach leaves a very wide margin of discretion to states on how to contribute to the endeavour of tackling climate change.

Over the years, UNFCCC Parties have adopted procedures to review what they have pledged to do. ${ }^{35}$ The mechanisms established to address this tricky question have only recently been tested, and it is therefore early to say how they will perform in the long run. One evident stumbling block, however, was that Parties have reported their pledges as they saw fit - for example, choosing different years as a baseline to measure their emission reductions - thus engendering a great deal of confusion as to what they are actually committing to do. Another was the absence of a mechanism to ratchet up ambition. So, while ahead of the Paris Conference the climate regime had made some strides in creating an intergovernmental process to encapsulate and review Parties' bottom-up efforts, more work in this direction was needed.

The Paris Agreement has arguably addressed this need, by sketching out a framework to review both progress towards achieving the global goal, as well as each Party's contribution to it. This review process will build upon and enhance extant arrangements under the UNFCCC. ${ }^{36}$ Although the details of largely remain to be determined, the Paris Agreement provides that Parties will submit their NDCs every 5 years, ${ }^{37}$ whereas the first global stocktake to inform parties in updating and enhancing their action is set to take place in 2023 , and every 5 years thereafter. ${ }^{38}$

The establishment of an institutionalized process to assess the adequacy of action in light of science was perceived as an indispensible element of the agreement, to ensure its

\footnotetext{
${ }^{31}$ Decision 2/CP.15, Copenhagen Accord, FCCC/CP/2009/11/Add.1.

${ }^{32}$ Kyoto Protocol, Annex B.

${ }^{33}$ Lavanya Rajamani, 'From Berlin to Bali and beyond: Killing Kyoto Softly [article]' (2008) 57 International and Comparative Law Quarterly 909; and Daniel Bodansky, 'W[h]ither the Kyoto Protocol? Durban and Beyond' (Harvard Project on Climate Agreements 2011) <http://www.c2es.org/docUploads/whither-kyotoprotocol-durban-and-beyond.pdf $>$.

${ }^{34}$ See for example Daniel Bodansky and Elliott Diringer, 'The Evolution of Multilateral Regimes: Implications for Climate Change' (Pew Center on Global Climate Change 2010) $<$ http://www.pewclimate.org/docUploads/evolution-multilateral-regimes-implications-climate-change.pdf $>$; and Daniel Bodansky, 'A Tale of Two Architectures: The Once and Future U.N. Climate Change Regime' (2011) $<$ http://papers.ssrn.com/abstract $=1773865>$.

${ }^{35}$ Decision 1/CP.16, Cancun Agreements, FCCC/CP/2010/7/Add.1, at 44-46 and 63-64.

${ }^{36}$ Paris Agreement, Article 13.4 and 13.13.

${ }^{37}$ Paris Agreement, Article 4.9.

${ }^{38}$ Paris Agreement, Article 14.2.
} 
durability, flexibility and alignment with the evolution of scientific knowledge. Combined with the non-back-sliding clause included in the operative part of the agreement, ${ }^{39}$ the global stock-take ensures the means to ratchet up the level of ambition over time, something that was sorely missing in the Kyoto Protocol.

The Paris Agreement thus builds on and institutionalizes the bottom up architecture emerged after the Copenhagen debacle, endowing it with measures for the review and the ratcheting up of ambition. Therefore, not only does the Paris Agreement provide an obligation for all to make efforts to reduce their emissions, it also sets the basis for the building of an architecture to review action, and enhance it, when needed. And whilst it is already clear that Parties' proposed contributions submitted to date are far from sufficient to achieve the goal identified in the Paris Agreement, in theory at least there will be means to revise and increase the level of ambition. How this will happen in practice, however, remains to be seen. The same may be said with regard to the expert-based, facilitative compliance mechanism to be established under the Paris Agreement. ${ }^{40}$ In this regard, the adoption of the agreement is just the beginning of a new regulatory season, whereby Parties will flesh out the processes and the rules to assist its implementation. ${ }^{41}$

\section{Differentiation}

While the extent of states' adherence to obligations embedded in the Paris Agreement remains to be seen, the agreement potentially provides an historical ' $U$-turn' ${ }^{42}$ in international climate governance on the vexed question of differentiation.

The UNFCCC famously built a firewall between developed and developing countries, by drawing a neat distinction between groups of Parties, relying on a static differentiation based on Organization for Economic Co-operation and Development (OECD) membership in 1992. With emissions in developing countries overtaking emissions in developed ones at the aggregate level, this static approach to differentiation has clearly proven inadequate to tackle climate change. Still for years Parties had been unable to reconsider the sensitive and divisive question of differentiation.

The Paris Agreement for the first time unequivocally establishes that all parties 'aim to reach global peaking of greenhouse gas emissions as soon as possible, ${ }^{, 43}$ asking each and all to undertake and communicate 'ambitious efforts' to achieve the purpose of the agreement. ${ }^{44}$ Furthermore, the agreement dismantles the firewall between developed and developing countries' obligations, at least partially. While developed countries should still 'continue taking the lead' in reducing their emissions, and are required to provide support to developing countries, ${ }^{45}$ the agreement also 'encourages' developing countries to move

\footnotetext{
${ }^{39}$ Paris Agreement, Article 4.3.

${ }^{40}$ Paris Agreement, Article 15.

${ }^{41}$ On the law-making powers of COPs, see Robin R Churchill and Geir Ulfstein, 'Autonomous Institutional Arrangements in Multilateral Environmental Agreements: A Little-Noticed Phenomenon in International Law' (2000) 94 The American Journal of International Law 623, at 638-641.

${ }^{42}$ UN Secretary General Ban Ki-moon statement in the closing hours of the Paris Climate Change Conference, notes on file with the author.

${ }^{43}$ Paris Agreement, Article 4.1.

${ }^{44}$ Paris Agreement, Article 3.

${ }^{45}$ Paris Agreement, Article 4.4 and 4.5.
} 
'towards economy-wide emission reduction of limitation targets, in light of different national circumstances. ${ }^{46}$

The Paris Agreement therefore requests all parties to make efforts to reduce their emissions $^{47}$ and to submit information on the details. In this connection, the agreement introduces a nuanced approach to differentiation, providing less stringent requirements for least developing countries and small island developing states, while levelling the reporting obligations for the others. ${ }^{48}$ This levelling is expected to engender a considerable secondary rules development process. ${ }^{49}$

In other respects, the agreement maintains a bifurcated approach, which is nevertheless more nuanced than that under the UNFCCC and the Kyoto Protocol. For example, on finance, the agreement largely maintains the Convention's approach, by imposing an obligation on developed countries to assist developing ones both in relation to mitigation and adaptation. Yet, it also encourages other Parties to provide financial support on a voluntary basis. ${ }^{50}$

One of the most innovative features of the Paris Agreement is an obligation concerning the reporting not only of action undertaken, but also of support provided and received. ${ }^{51}$ Again, the modalities and procedures for such reporting remain to be determined. ${ }^{52}$ But the agreement establishes a technical review process, which will consider both Parties' action, as well as support provided. ${ }^{53}$ This review is entrusted to identify areas of improvement ${ }^{54}$ thus providing an element of novelty compared with extant arrangements, which it is eventually meant to supersede. ${ }^{55}$

\section{Climate justice and loss and damage}

The preamble of the Paris Agreement contains an unprecedented reference to the difficult and vexed question of so called 'climate justice.' The issue of climate justice has attracted much attention in the debate on the future of the climate regime. The term has been used to refer to distributive and corrective justice considerations associated both with the impacts of climate change and of climate change response measures. It is therefore inherently linked with that on equity in the climate regime, and ultimately revolves around how to share the burdens associated with a global transition towards low-carbon societies. ${ }^{56}$

In a controversial monograph published in 2010, Posner and Weisbach famously argued that that international climate law should not attempt to reflect principles of corrective or distributive justice. ${ }^{57}$ In fact, the authors maintained that competing claims about justice

\footnotetext{
${ }^{46}$ Paris Agreement, Article 4.4.

${ }^{47}$ Paris Agreement, Article 3.

${ }^{48}$ Paris Agreement, Article 4.6.

49 Paris Agreement, Article 4.8-4.13.

${ }^{50}$ Paris Agreement, Article 9.1 and 9.2.

${ }^{51}$ Paris Agreement, Article 13.

${ }^{52}$ Paris Agreement, Article 13.13.

${ }^{53}$ Paris Agreement, Article 13.11.

${ }^{54}$ Paris Agreement, Article 13.12.

${ }^{55}$ Decision 1/CP.21, at 99.

${ }^{56}$ Christina Voigt, 'Equity in the 2015 Climate Agreement' (2014) 4 Climate Law 50; and Harald Winkler and Lavanya Rajamani, 'CBDR\&RC in a Regime Applicable to All' (2014) 14 Climate Policy 102.

${ }^{57}$ Eric A Posner and David Weisbach, Climate Change Justice (Princeton University Press 2010).
} 
are largely responsible for failure to agree on international action to tackle climate change. They therefore suggested that climate justice argumentations be left out of the climate regime altogether.

Contrariwise, numerous authors have noted how the climate regime inherently deals with the distribution of resources for climate change mitigation and adaptation, and the allocation of shares in a global carbon budget. ${ }^{58}$ These authors conclude that solving the climate problem is impossible without addressing justice considerations, most notably, those concerning the transfer of capacity, finance and technologies to tackle climate change. ${ }^{59}$

The Paris Agreement has tiptoed around these complex and contentious issues. On corrective justice, the Paris Agreement addresses for the first time in a treaty the contentious matter of loss and damage caused by climate change. There is a great deal of ambiguity in the agreement on how this complex issue will be addressed. The Paris Agreement does little more than acknowledge extant institutional arrangements, without encapsulating a reference to a climate change displacement coordination facility, which had appeared in earlier drafts of the text.

The matter of the organized migration and planned relocation of populations forced to move as a result of climate change has long been an elephant in the room at climate negotiations. In this regard, some developed countries insisted, and eventually obtained, that the text of the COP decision accompanying the Paris Agreement specify that the provision of loss and damage 'does not involve or provide a basis for any liability or compensation. ${ }^{60}$ Instead, the decision provides some consideration for the issue of displacement, by establishing a process to develop recommendations for approaches to avert, minimise and address displacement. ${ }^{61}$ Furthermore, extant institutions are entrusted to establish a clearinghouse that serves as a repository for information on insurance and risk transfer, in order to facilitate the efforts of Parties to develop and implement comprehensive risk management strategies. ${ }^{62}$

As far as matter of distributive justice is concerned, the picture emerging from the Paris Agreement is even more opaque. While in fact the COP decision accompanying the Paris Agreement makes reference to a collective quantified goal for support to developing countries, it does not go very far in establishing new obligations in connection with adaptation and finance. ${ }^{63}$

\section{Human rights}

The Paris Agreement has provided a marginal victory for those advocating for building bridges between the climate regime and human rights law, including the UN Secretary General Special Envoy on Climate Change, Mary Robinson.

\footnotetext{
${ }^{58}$ See for example Friedrich Soltau, Fairness in International Climate Change Law and Policy (Cambridge University Press 2009).

${ }^{59}$ See for example the papers included in Stephen Humphreys, Human Rights and Climate Change (Cambridge University Press 2009).

${ }^{60}$ Decision 1/CP.21, at 52 .

${ }^{61}$ Decision $1 / \mathrm{CP} .21$, at 50 .

${ }^{62}$ Decision $1 /$ CP.21, at 49.

${ }^{63}$ As argued also in Daniel Bodansky, 'Is the Paris Agreement Historic?' < http://opiniojuris.org/2015/12/13/itthe-paris-agreement-historic/> accessed 14 December 2015.
} 
The adverse effects of climate change threaten the enjoyment of a range of human rights, such as the right to life, adequate food, the highest attainable standard of health, adequate housing, and to safe drinking water and sanitation. Yet, not all UNFCCC Parties have ratified international or regional human rights treaties. Numerous states, moreover, have resisted the suggestion that human rights treaties apply extraterritorially. ${ }^{64}$ Thus while some human rights bodies have endorsed the view that states may have human rights obligations towards those beyond their jurisdiction, most states maintain that their human rights obligations are territorially limited and only cover individuals, groups or legal entities within their jurisdiction. The latter states are, therefore, unlikely to accept that they have obligations to undertake positive action to secure the protection of human rights associated with climate change impacts beyond their territory.

A distinction also needs to be drawn between the impacts on the enjoyment of human rights caused by climate change, and by climate change response measures. The first require states to temper the negative impacts on the enjoyment of human rights associated with a changing climate. Conversely, with climate change response measures, the matter is rather to ensure that adaptation and mitigation actions and policies do not unduly affect the enjoyment of human rights. In both cases, human rights law and practice may assist in the making and implementation of climate law.

First, UNFCCC parties could draft and interpret rules to address the impact of climate change and of climate change response measures by building upon substantive and procedural obligations included in human rights instruments. Second, international and regional human rights bodies may provide institutionalized pathways to monitor and sanction human rights violations associated with climate change and the implementation of climate change response measures. International human rights bodies have acknowledged these synergies, affirming that human rights obligations and commitments have the potential to 'inform and strengthen' international and national climate policymaking, promoting 'policy coherence, legitimacy and sustainable outcomes. ${ }^{65}$

This potential has been increasingly discussed at climate negotiations. The climate regime had already broken new grounds in 2010, by adopting a COP decision emphasizing that Parties 'should, in all climate change related actions, fully respect human rights, ${ }^{66}$ as well as the need to engage a broad range of stakeholders at the global, regional, national and local levels, adding that 'effective participation of women and indigenous peoples are important for effective action on all aspects of climate change. ${ }^{, 67}$

The Paris Agreement is the first multilateral environmental agreement to explicitly make reference to human rights. ${ }^{68}$ Iterations of the draft text of the Paris Agreement included

\footnotetext{
${ }^{64}$ Perhaps with the sole exception of economic, social and cultural rights. See Report of the Independent Expert on the issue of human rights obligations relating to the enjoyment of a safe, clean, healthy and sustainable environment, John H Knox, A/HRC/25/53, at 62-68.

${ }^{65}$ See for example: Human Rights Council Resolution 10/4 (2009), A/HRC/RES/10/4 Preamble.

${ }^{66}$ Decision $1 / \mathrm{CP} .16$, at 8 .

${ }^{67}$ Ibid., at 7.

${ }^{68}$ John H Knox, 'Mapping Human Rights Obligations Relating to the Enjoyment of a Safe, Clean, Healthy and Sustainable Environment. Individual Report on Global and Regional Environmental Agreements' (Office of the United Nations High Commissioner for Human Rights 2013)
} 
references to human rights and the rights of indigenous peoples in the substantive part of the treaty, ${ }^{69}$ which were later expunged. The only remaining references to human rights is in agreement's preamble, which mentions human rights, the rights of indigenous rights and local communities, and the concept of climate justice. These preambular references do not configure new and separate legal obligations for Parties to the Paris Agreement. They merely draw Parties' attention to obligations they have already undertaken under the human rights treaties they ratified, or may ratify in future, and to relevant customary norms and domestic laws. Even so, preamble text has political and moral value, drawing an explicit link between treaty obligations under the climate regime and those under the human rights instruments they have ratified. It flags that Parties are expected to interpret their obligations under the Paris Agreement in light of their existing human rights obligations concerning matters such as, for example, public participation, the rights of women and indigenous peoples.

\section{Looking ahead: a new season for climate governance?}

The Paris Agreement will be opened for signature on 22 April 2016, which will also mark the celebration of Earth Day. Beyond this symbolic milestone, there seems to be much worth celebrating about the Paris Agreement. The agreement encompasses new elements, which were missing or inadequately addressed in the climate architecture.

It adopts a collective long term goal on climate change mitigation, to be supported by efforts from all Parties. It establishes a periodic process for the submission of information on Parties' efforts, as well as a process for their review, both at the individual, as well as at the aggregate level. It has dismantled the differentiation firewall, replacing it with a more flexible approach, which arguably still hinges on equity. The agreement furthermore for the first time recognizes the role of non-state actors in addressing climate change, ${ }^{70}$ and raises the profile of adaptation, albeit only incrementally. ${ }^{71}$

Perhaps more importantly, the Paris Agreement seemingly marks a new season in international climate diplomacy, with the emergence of a cooperative spirit that will hopefully continue in the years to come, breaking away from the rancorous and largely circular and sterile rhetoric that has long characterized international climate negotiations. The regulatory process set to begin in 2016 will reveal whether the Paris Conference has indeed marked a palingenesis.

Whether the Paris Agreement will prove fit for purpose, and how it will be implemented, remains to be seen. Yet it has undoubtedly restored faith in international climate governance and in multilateralism, creating the premises for a process to address climate change in the long term. Though not perfect, the agreement represents a fairly balanced compromise, probably the best that could be achieved at this time and in these circumstances.

The Paris Agreement, nevertheless, leaves unaddressed a series of difficult questions.

\footnotetext{
$<$ http://www.ohchr.org/EN/Issues/Environment/SREnvironment/Pages/MappingReport.aspx $>$ accessed 14 December 2015, at 9.

${ }^{69}$ Annalisa Savaresi and Jacques Hartmann, 'Human Rights in the 2015 Agreement' (Legal Response Initiative 2015).

${ }^{70}$ Paris Agreement, Preamble.

${ }^{71}$ Paris Agreement, Article 7.
} 
To mention just a couple, the agreement sheds no light on the future of the Kyoto Protocol. The COP decision adopting the Paris Agreement ritually encourages Parties to ratify the Doha Amendment to the Kyoto Protocol, which includes targets for the second commitment period and is yet to enter into force. ${ }^{72}$ There is little doubt that in the coming years UNFCCC Parties will have to decide what to do with this embattled treaty, which includes no twilight clause, but has been clearly superseded by circumstances.

Another issue that remains to be determined is the extent to which the Paris Agreement will facilitate voluntary cooperation in the implementation of Parties' action, including through market and non-market based approaches. While the agreement provides some generic references to these issues, ${ }^{73}$ the devil is in the details, and much work will be needed to craft the rules to operationalize these provisions.

It would therefore be naïve to expect the Paris Agreement to be a miraculous cure for all the maladies of the climate regime. As many delegates remarked in the closing hours of the Paris Conference, the hard work lies ahead. After Paris, however, climate negotiators can undertake this task in a considerably much hopeful mood, certainly the most hopeful they have been for quite some time.

\footnotetext{
${ }^{72}$ Decision 1/CP.21, at 106.

${ }^{73}$ Paris Agreement, Article 6.
} 